\title{
Evolução do Uso da Web pelos Bancos
}

\author{
Eduardo Diniz
}

\section{RESUMO}

Este artigo pretende caracterizar a evolução do uso da Web pelos bancos, utilizando-se para isso do estudo de cerca de 300 Web sites de bancos em três países - Brasil, Estados Unidos e Espanha durante um período de dois anos entre 1997 e 1999. O artigo analisa os resultados obtidos na pesquisa à luz do que está publicado em literatura sobre o tema. O modelo de análise usado neste estudo classifica os serviços bancários oferecidos nos sites dos bancos em três grupos principais: divulgação, transação e relacionamento. Cada um destes grupos está subdividido em três outros, com base no nível de interação dos usuários com o site, compondo um total de nove diferentes categorias. Observou-se que os bancos primeiro viram a Web como um canal útil para promoção de seus produtos e serviços. Num outro momento, a Web passou a ser considerada como uma alternativa para a redução dos custos das transações bancárias e também como instrumento para intensificar o relacionamento dos bancos com seus clientes, a partir da utilização de serviços cada vez mais interativos.

Palavras-chaves: Internet; serviços bancários; comércio eletrônico; banco virtual.

\begin{abstract}
This paper presents an analysis of the Web banking evolution based on a survey on 300 bank Web sites in three countries - Brazil, United States and Spain - from 1997 to 1999. Looking at works that have being published on the subject, this paper classifies banking services in three main groups: information delivery, transaction and relationship. Each of these three groups is divided in other three, depending on interactivity level of the service, creating nine different categories. First banks went to the Web to post promotional information about products and services. Later they discovered the opportunities to reduce costs and improve relationship with clients through the use of more interactive services.
\end{abstract}

Key words: Internet; banking services; electronic commerce; home banking. 


\section{INTRODUÇĀO}

O comércio eletrônico é uma das tendências com maior poder de inovação nos processos de negócio (Albertin, 1998). Conhecer, portanto, as estratégias que os bancos estão utilizando, para implantar serviços na Web, contribui para o melhor entendimento da evolução do comércio eletrônico no setor financeiro. Conhecendo a evolução dos serviços bancários pela Web, pode-se entender os desafios estratégicos e as questões que estas empresas estão enfrentando para identificar e implementar alternativas de comércio eletrônico no setor.

Este artigo baseia sua argumentação em literatura publicada - especialmente relatórios de pesquisa e working papers - sobre o uso da Web pelos bancos e também na observação de Web sites de bancos no Brasil, Estados Unidos e Espanha que vem sendo feita pelo autor desde 1997.

\section{Crescimento do Uso do Home Banking}

Desde a década de 70 se ouvem promessas sobre o inevitável banco eletrônico que se tornaria acessível virtualmente. A frustração dessas promessas levanta a descrença de alguns (White, 1997) no novo boom anunciado para o home banking. Kalakota e Whinston (1997) entretanto argumentam que alguns fatores serão responsáveis pela consolidação do home banking. Entre estes fatores destaca-se este elenco:

. a curva de aprendizado dos usuários dos serviços bancários, que estão tornando-se cada vez mais habilitados no uso de computadores;

. uma consciência maior por parte dos mesmos usuários dos bancos sobre as possibilidades do home banking, devido até ao próprio marketing dos bancos, nunca antes tão forte na divulgação do potencial do banco virtual;

- a busca de alternativas para a redução do custo de processamento de transações;

- a base instalada de PCs com modems nas residências, que nunca foi tão grande e continua crescendo a taxas vigorosas;

- a competição sofrida pelos bancos por empresas não bancárias na oferta de serviços on-line. 
De fato, se tomarmos o exemplo mencionado por Seybold (1998), de 1989 a 1995 o banco californiano Wells Fargo manteve um total de 20.000 clientes do seu software de home banking; entretanto, em apenas um dia de maio de 1995, o Wells Fargo recebeu um total de 1.500 inscrições para utilização de serviços bancários por meio da Web. Era o primeiro dia de abertura do serviço naquele que foi um dos primeiros bancos a oferecer um site na Web com possibilidade de realização de transações bancárias.

Em meados de 1998, o Wells Fargo já havia cadastrado mais de 470.000 usuários on-line; portanto, além dos fatores mencionados anteriormente, o que certamente influenciou os clientes do Wells Fargo para a utilização do home banking foi o crescimento da Internet e a oferta dos serviços bancários pela Web.

O caso do Wells Fargo está longe de ser único. Apesar do crescimento da oferta de serviços de home banking via Web ter sido constatado em diversos países, freqüentemente o principal comentário era que o serviço estava ainda no início e muito ainda deveria evoluir (Pecenik, 1996; Sathye, 1997; Gallego, 1998). Estas descrições em tom de crítica quanto à lentidão dos bancos para a implementação de serviços pela Web podem também ser interpretadas como expressão da crescente demanda por estes serviços, proporcional ao explosivo crescimento da Web entre os usuários.

Assim, entre as estratégias de home banking tentadas nos últimos anos pelos bancos, a de maior sucesso recente e que tem alavancado a utilização do home banking em todo o mundo é aquela que vamos denominar aqui de Web banking. Outras alternativas de home banking utilizadas (principalmente nos Estados Unidos) pelos bancos foram:

. softwares proprietários fornecidos pelos bancos;

- utilização de softwares de administração financeira (Quicken e Money, por exemplo), conectados a dados fornecidos pelos bancos por meio de linha discada;

. utilização de serviços on-line para fornecimento de informações bancárias (AOL nos Estados Unidos e videotexto no Brasil).

Basicamente o que diferencia essas soluções do Web banking é o fato de ele ser baseado num modelo de utilização de sistemas abertos, que é característica da Internet. Em primeiro lugar, numa solução aberta, os softwares utilizados pelo usuário do home banking (browsers da Web) são de conhecimento público e o banco não precisa preocupar-se em treinar ninguém para o uso de um software específico. Além disso, a atualização de versões não implica a substituição de softwares já distribuídos aos usuários, pois é feita apenas no servidor do banco. 
E também muito importante é o fato de que o banco, por meio da Web, mantém maior controle de sua imagem e marca, o que não acontece se o home banking é feito por meio de softwares de terceiros, como a Microsoft ou a AOL, por exemplo.

Ainda o fato de ser apoiada por um protocolo de comunicação, com possibilidades de multimídia e de já ter uma base instalada de muitos milhões de usuários (empresas e indivíduos), coloca a Internet em grande vantagem, comparada com as soluções proprietárias (Cipparone, 1996).

Além do varejo, diretamente ligado ao uso do home banking, outra importante área de atuação dos bancos, que deve sofrer maior impacto com o uso da Web, é a de investimento (Kalakota e Whinston, 1997). Estas duas áreas, por serem as mais afetadas por inovações tecnológicas, são as que têm maior probabilidade de lucrar com o desenvolvimento do comércio eletrônico.

\section{Modelo de ANÁlise}

Para se estabelecerem parâmetros de análise do uso da Web pelos bancos, foi criado um modelo de classificação dos serviços oferecidos nos seus sites. As atividades e serviços bancários oferecidos pela Web podem ser classificados de diversas formas. Uma possibilidade é a classificação da funcionalidade dos Web sites de tal forma que destaque as oportunidades que podem ser aproveitadas pelos bancos em três categorias de serviços:

. como veículo para difusão de informação, que tanto pode ser utilizado para a distribuição de informações de negócio quanto de publicidade da empresa e seus produtos;

. como canal para operar transações, da mesma forma que agências e caixaseletrônicos;

. como ferramenta para aprimorar o relacionamento com os clientes.

Dividindo cada uma das categorias de atividades descritas previamente - difusão de informação, canal para realização de transações e relacionamento com o cliente - nos três diferentes níveis de interatividade - básico, intermediário e avançado - obtém-se nove subdivisões apresentadas no Quadro 1, a seguir.

No primeiro nível, que denominamos básico ou incremental, um banco apenas reproduz no Web site as possibilidades que já explora em outros canais. Isto abre nova frente de atuação, mas ainda sem explorar todas as possibilidades específicas da Web. No nível seguinte, o intermediário, algumas características 
específicas da Web já são utilizadas para incrementar os serviços oferecidos pelo banco. No terceiro nível, o avançado, estão as utilizações da Web que abrem possibilidades para a criação de novas oportunidades de negócio.

\section{Quadro 1: Classificação dos Serviços Oferecidos nos Sites dos Bancos}

\begin{tabular}{|c|c|c|c|}
\hline & Básico & Intermediário & Avançado \\
\hline Divulgação & $\begin{array}{l}\text { - brochura } \\
\text { eletrônica }\end{array}$ & $\begin{array}{l}\text { - busca } \\
\text { - links }\end{array}$ & $\begin{array}{l}\text { - customização } \\
\text { - assinatura }\end{array}$ \\
\hline Transação & $\begin{array}{l}\text { - abrir conta } \\
\text { - solicitar } \\
\text { produtos }\end{array}$ & $\begin{array}{l}\text { - saldo/extrato } \\
\text { - transferência } \\
\text { - pagamentos }\end{array}$ & $\begin{array}{l}\text { - banco sem } \\
\text { agência } \\
\text { - promoção }\end{array}$ \\
\hline $\begin{array}{l}\text { Relaciona- } \\
\text { mento }\end{array}$ & $\begin{array}{l}\text { - e-mail } \\
\text { - formulários }\end{array}$ & $\begin{array}{l}\text { - calculadoras } \\
\text { - perfil de } \\
\text { investidor }\end{array}$ & $\begin{array}{l}\text { - fórums } \\
\text { - chat }\end{array}$ \\
\hline
\end{tabular}

É importante observar que estamos classificando os serviços oferecidos e não os sites em si para melhor identificar as oportunidades de negócio. Devido à diversidade das empresas no mercado bancário e à variedade possível na oferta de serviços, é comum observar um site oferecendo um serviço inovador e avançado numa categoria e diversos serviços básicos em outra, o que deixa sem muito sentido classificar o site de uma forma ou de outra. Há também que se considerar que a Web está em meio a um processo evolutivo extremamente rápido, o que pode transformar os serviços avançados em básicos em curtos períodos.

Embora tenha sofrido algumas pequenas modificações ao longo de quase dois anos de sua utilização, este modelo permitiu organizar a coleta de informações sobre serviços oferecidos em quase 300 sites de três países (Brasil, Estados Unidos e Espanha).

O levantamento de informações em sites de bancos de diferentes países teve o objetivo de verificar a eficácia do instrumento de coleta e análise de dados sobre serviços bancários na Web e não comparar os sistemas bancários da Espanha, do Brasil e dos Estados Unidos; entretanto a comparação do Web banking nestes países pôde indicar alguns aspectos da influência de fatores regulatórios e culturais na oferta de serviços bancários.

A inclusão no estudo de bancos dos Estados Unidos permitiu avaliar a situação num universo em que a utilização da Web é mais ampla e no qual o comér- 
cio eletrônico está em estágio mais avançado do que em qualquer outro. Os números sobre o uso da Web nos Estados Unidos são contundentes e a experiência do país nesse setor é inegável, o que torna os Estados Unidos um parâmetro obrigatório para comparar qualquer coisa que diga respeito a comércio eletrônico. A inclusão da Espanha no estudo possibilita uma observação num país europeu, de cultura latina e também de dimensões econômicas e de sistema bancário mais próximos aos brasileiros. Outro motivo para analisar sites na Espanha e nos Estados Unidos é a crescente importância de bancos destes países no mercado brasileiro.

Tabela 1: Composição da Amostra Estudada

\begin{tabular}{|c|c|c|c|}
\hline \multicolumn{3}{|l|}{ Espanha } & Mar/99 \\
\hline \multicolumn{3}{|l|}{ Total de sites analisados } & 64 \\
\hline \multicolumn{3}{|l|}{ Bancos } & $32,8 \%$ \\
\hline \multicolumn{3}{|l|}{ Cajas } & $67,1 \%$ \\
\hline \multicolumn{2}{|l|}{ Estados Unidos } & Nov/97 & Jan/99 \\
\hline \multicolumn{2}{|l|}{ Total de sites analisados } & 121 & 152 \\
\hline \multicolumn{2}{|l|}{ Ativos $>$ US $\$ 10$ bilhões } & $20,7 \%$ & $24,3 \%$ \\
\hline \multicolumn{2}{|c|}{ US\$500 milhões $<$ ativos $<$ US $\$ 10$ bilhões } & $32,2 \%$ & $28,3 \%$ \\
\hline \multicolumn{2}{|l|}{ Ativos $<$ US\$500 milhões } & $47,1 \%$ & $47,4 \%$ \\
\hline Brasil & Jun/97 & Mai/98 & Mai/99 \\
\hline Total de sites analisados & 55 & 73 & 81 \\
\hline Ativos $>2 \%$ do total & $12,7 \%$ & $12,3 \%$ & $13,6 \%$ \\
\hline $2 \%>$ ativos $>0,2 \%$ do total & $52,7 \%$ & $46,6 \%$ & $45,7 \%$ \\
\hline Ativos $<0,2 \%$ do total & $34,5 \%$ & $41,1 \%$ & $40,7 \%$ \\
\hline
\end{tabular}

A Tabela 1 caracteriza as amostras estudadas para subsidiar as conclusões deste artigo. Foram feitas pesquisas entre 1997 e 1999 no Brasil, nos Estados Unidos e na Espanha. Na Espanha as cajas representam bancos de menor porte. No caso de Brasil e Espanha, a análise contemplou praticamente todos os sites em funcionamento normal nos dois países, sendo excluídos aqueles com apenas uma página avisando que o site estava em fase de reformulação. Nos Estados Unidos procurou-se manter uma amostra que contivesse uma composição arbitrária, contendo $20 \%$ de bancos grandes, $30 \%$ de bancos de porte intermediário e $50 \%$ de bancos pequenos, nas duas etapas de coleta de dados. Esta composição aumenta a proporção de bancos maiores com relação ao universo, ampliando a 
capacidade de observação entre os que mais investem em novas tecnologias, mas também mantém uma alta proporção dos bancos menores, que representam o perfil da maioria dos bancos do país.

\section{A Web E os BANCOS}

A observação de Web sites de bancos nos últimos anos mostra que os serviços bancários pela Internet vêm evoluindo em qualidade e quantidade. Da literatura sobre o tema notamos que os argumentos para explicar por que os bancos devem utilizar a Web também se modificam com o tempo. O cruzamento da informação encontrada na literatura com a observação dos serviços oferecidos nos sites pode apontar uma tendência na evolução do Web banking.

Vamos a seguir descrever a evolução das estratégias predominantes de implementação de serviços bancários pela Web.

\section{Web como Canal de Promoção e Divulgação}

A velocidade de crescimento da Internet a coloca em evidência como canal de promoção privilegiado para qualquer empresa. Em particular para os bancos, que estão entre as empresas que mais investem em tecnologia, a Web atinge uma parcela de clientes mais afluentes e de grau mais elevado de escolaridade, como comprovam algumas pesquisas sobre o perfil do usuário da Web (Diaz e Gertner, 1998; Gonçalves Filho et al., 1998; Vieira, Viana e Echeveste, 1998).

Além disso, existe a necessidade de os bancos explorarem a sua imagem de empresas avançadas tecnologicamente. Bancos em diversas partes do mundo competem, apresentando-se como empresas que oferecem aos seus clientes o que há de mais avançado em termos de tecnologia. A utilização da Web, um ícone das novas tecnologias, está assim em sintonia com essa abordagem de marketing pelos bancos.

A Web se destaca por prover informação por meio de comunicação de dupla mão com o usuário (Seitz e Stickel, 1998). Isto significa que, na sua forma mais simples, além de publicar informações sobre a organização e sobre seus produtos e serviços, os bancos podem também receber mensagens eletrônicas de seus clientes, abrindo assim a possibilidade para que eles solicitem mais informações, façam queixas e apresentem sugestões.

Em nível um pouco mais sofisticado, o banco pode utilizar informações reco- 
lhidas anteriormente do cliente para poder oferecer seletivamente a ele apenas aqueles produtos que poderiam interessar-lhe diretamente, evitando assim sobrecarregá-lo com informações que não lhe são úteis, criando uma forma de interação personalizada.

Sofisticando mais ainda a forma de apresentação dos seus produtos, o banco pode fazer com que o cliente teste alguns produtos antes de optar pela sua aquisição. É o caso de carteiras de investimento, que podem ser montadas pelo cliente e ter o seu desempenho monitorado através de um período de tempo, simulando assim um investimento antes mesmo de se decidir pela efetivação da transação.

É importante lembrar que, em todos os casos mencionados anteriormente, espera-se uma postura muito mais ativa por parte do cliente do que o que acontece diante de outros canais tradicionais de promoção e divulgação de produtos. Este foco no cliente mais ativo está em sintonia com a estratégia de atender ao perfil dos usuários da Web, mais dispostos a ir buscar a informação sobre os produtos e serviços que lhes interessam.

As pesquisas realizadas em Web sites demonstram que a maior parte dos bancos já assimilou a Internet como canal de promoção e divulgação. Desde 1997, todos os sites analisados usam a Web no mínimo para oferecer aos usuários dos sites, sejam eles clientes atuais ou potenciais, acionistas, fornecedores, investidores ou outros, a simples divulgação de informações sem uso de recursos interativos. É a caracterização da predominância dos serviços descritos no modelo apresentado na seção anterior como sendo de divulgação básica.

Além da descrição de produtos e serviços oferecidos pelos bancos, as informações mais comuns encontradas nos sites analisados no Brasil, nos Estados Unidos e na Espanha são informações financeiras sobre o mercado e o próprio banco, canal de notícias, informações sobre a comunidade, endereços de agências e postos de serviço, tarifas dos serviços e rentabilidade dos produtos, e informações sobre quem são os executivos dos bancos (Diniz, 1999a, 1996b, 1999c).

A adoção integral destes serviços básicos de promoção e divulgação por meio da Web é devida à sua simplicidade e baixo custo de implementação. Além disso, a implantação de um site na Web está associada à ocupação de nomes de domínio na Internet, na maioria das vezes ligados ao uso de marca registrada dos bancos. Empresas que demoraram para registrar seu domínio na Internet tiveram problemas para conquistar legalmente nomes que já utilizavam há muito anos, mas que foram registrados na Internet sob o controle de outros ${ }^{(1)}$.

Ainda assim, a utilização pelos bancos de recursos mais interativos da Web para divulgação de informações é menos unânime. Se considerarmos os serviços na categoria de divulgação intermediária, observamos que os bancos no 
Brasil evoluíram de 58\% para 64\% entre 1997 e 1998, para 81\% em 1999 (Diniz, 1999a, 1999b, 1999c). Note-se que estes serviços incluem a utilização de recursos ainda muito elementares da Web, como links e ferramentas de busca. Nos bancos dos Estados Unidos, os serviços desta categoria passaram de um nível de utilização de 64\% em novembro de 1997 para 89\% em janeiro de 1999 (Diniz, 1999a). Já os bancos na Espanha estavam em 87\% de utilização desta categoria de serviços em março de 1999 (Diniz, 1999b).

Quanto aos serviços na categoria de divulgação avançada, os índices de utilização estão ainda em patamares muito mais baixos. Como mostra a Tabela 2, em 1999, enquanto no Brasil estes serviços eram utilizados por $10 \%$ dos bancos, na Espanha o nível de utilização era de apenas 2\%. Nos Estados Unidos, 24\% dos bancos usavam algum tipo de serviço nesta categoria no início de 1999.

Tabela 2: Serviços de Divulgação

\begin{tabular}{|l|c|c|c|}
\hline & $\begin{array}{c}\text { Divulgação } \\
\text { básica }\end{array}$ & $\begin{array}{c}\text { Divulgação } \\
\text { intermediária }\end{array}$ & $\begin{array}{c}\text { Divulgação } \\
\text { avançada }\end{array}$ \\
\hline Brasil (maio/1999) & $100 \%$ & $81 \%$ & $10 \%$ \\
\hline Estados Unidos (janeiro/1999) & $100 \%$ & $89 \%$ & $24 \%$ \\
\hline Espanha (março/1999) & $100 \%$ & $89 \%$ & $2 \%$ \\
\hline
\end{tabular}

Das três categorias de divulgação, a básica ainda predomina; mas se percebe uma tendência de crescimento nos níveis de utilização de serviços das outras categorias, principalmente da intermediária. É de se esperar que a evolução da Web venha a incentivar também serviços bancários de divulgação mais interativos e originais, que seriam classificados na categoria avançada.

É preciso considerar também as diferenças e semelhanças entre os usuários de Web banking dos diferentes países. Há que se conhecer a proporção de usuários que é mais receptiva aos serviços mais interativos e verificar oportunidades de negócios que podem ser criadas com a utilização desses recursos específicos do canal Web.

\section{Redução de Custos de Transação}

Uma vez que um banco passa a divulgar informações pela Web, ele ocupa institucionalmente um espaço que deverá ser preservado, da mesma forma que se faz com um espaço físico qualquer de propriedade privada. Isso implica estabelecer critérios para ocupação institucional do ciberespaço, mas também ado- 
tar dispositivos de segurança para proteger o site. Nenhuma empresa deixaria o seu site, mesmo aquele que contenha apenas informações institucionais, acessível ao ataque de hackers, que pudessem alterar o conteúdo do que está ali publicado.

Segurança também é exigência básica para a oferta de serviços bancários de acesso a informações internas dos bancos de dados armazenados pelas empresas. O máximo de segurança nunca é demais, se estamos protegendo valores financeiros, exatamente a informação que é mais manipulada internamente nos bancos. Nenhum banco pode aventurar-se a oferecer qualquer tipo de transação, se não estiver absolutamente convencido do alto grau de segurança que pode oferecer aos seus clientes.

No modelo apresentado anteriormente, o nível de transação básico corresponde à solicitações de abertura de conta e à requisição de produtos e serviços como cartões de crédito e outras operações, que não envolvam a manipulação direta de fundos. Já no nível de transação intermediário, o cliente acessa informações sobre a sua conta no banco e pode mesmo transferir fundos, fazer investimentos e pagar contas. Note-se que no nível intermediário o cliente tem de acessar e autorizar alterações no banco de dados interno do banco. É evidente que o nível de segurança exigido para a implementação de serviços intermediários de transação é superior ao exigido no nível básico.

\section{Tabela 3: Serviços de Transação}

\begin{tabular}{|l|c|c|c|}
\hline & $\begin{array}{c}\text { Transação } \\
\text { básico }\end{array}$ & $\begin{array}{c}\text { Transação } \\
\text { intermediário }\end{array}$ & $\begin{array}{c}\text { Transação } \\
\text { avançado }\end{array}$ \\
\hline Brasil (maio/1999) & $41 \%$ & $36 \%$ & $9 \%$ \\
\hline Estados Unidos (janeiro/1999) & $68 \%$ & $45 \%$ & $9 \%$ \\
\hline Espanha (março/1999) & $75 \%$ & $78 \%$ & $8 \%$ \\
\hline
\end{tabular}

Curiosamente, como indica a Tabela 3, entre os bancos analisados no Brasil e na Espanha, a oferta de serviços de transação no nível básico é menos utilizada pelos bancos do que a de serviços do nível intermediário. Esta situação pode indicar que os bancos, nestes países, estão perdendo uma oportunidade de explorar melhor as alternativas de negócios pela Web que seriam possíveis com os níveis de segurança já implementados no site do banco. Por outro lado, estes serviços envolvem uma articulação mais estruturada do banco para a entrega do serviço solicitado, como talões de cheque ou cartões de crédito, por exemplo. Se o banco oferece a comodidade de o cliente solicitar o serviço pela Web, precisa também ter a mesma agilidade na sua entrega, o que nem sempre é fácil, porque depende de fatores que podem estar além do controle do próprio banco. 
Além do nível de utilização em determinado momento, também é importante observar a taxa de crescimento dos serviços dos diferentes níveis. No Brasil, o número de bancos que oferecem serviços de acesso a contas por meio da Internet cresceu $71 \%$ entre junho de 1997 e maio de 1998, e mais 33\% até maio de 1999 (Diniz, 1999a, 1999b, 1999c). Nos Estados Unidos, o crescimento da oferta do mesmo tipo de serviço nos treze meses entre novembro de 1997 e janeiro de 1999 foi de $114 \%$.

Estas taxas de crescimento nos dois países no curto período de cerca de um ano denunciam o alto grau de prioridade que os bancos estão dando a este tipo de implementação. Este grau de priorização deve estar associado, por um lado, ao crescente interesse dos usuários por este canal de acesso a suas contas com o banco. Na Espanha, onde foi feita apenas uma observação, os níveis de adoção de serviços nesta categoria são surpreendentemente altos, superando em mais de $70 \%$ o nível obtido nos Estados Unidos, país onde geralmente se considera que o uso do Internet banking é mais elevado.

Se os bancos oferecem estes serviços com mais freqüência é porque, em primeiro lugar, confiam na segurança de que a Web dispõe. Também estão interessados em associar a sua imagem com a oferta de serviços considerados de padrão tecnológico mais elevado, o que contribuiria para preservar a sua base de clientes. Ademais, as operações pela Web acenam com a possibilidade extremamente objetiva de redução dos custos de realização de transações. Corroborando estas afirmações, uma pesquisa indica que a retenção de clientes e a redução de custos são as duas principais razões que levam os bancos a desenvolver iniciativas de utilização da Internet (Ernst \& Young, 1999).

De fato, já é corrente a afirmação de que o custo de uma operação bancária via Internet custa cerca de $10 \%$ da efetuada em uma agência convencional (Gazeta Mercantil, 1997; Nehmzow, 1997). Mais recentemente, outras fontes apontam que o custo destas transações pela Web pode ser de até 1\% do custo da sua realização nas agências (Cuevas, 1998; Gates III, 1999).

A possibilidade de redução de custos de operação e transação tem sido um dos benefícios mais óbvios que as empresas esperam obter com a utilização da Web (Ware et al., 1998) e é também a motivação que tem prevalecido no curto prazo (Kalakota, 1997), como razão para os bancos utilizarem a Web. Esta redução de custos é esperada pela automação dos processos já existentes (Ernst \& Young, 1999).

Há que se considerar também que a Internet é uma rede baseada numa infraestrutura pública e aberta. Quanto mais ampla é uma rede e quanto maior o número de usuários, menor será o seu custo médio de operação (Cipparone, 1996). Isso faz com que os bancos busquem os baixos custos de operação e 
manutenção associados com a Web, uma vez que redes proprietárias são economicamente menos eficientes.

A redução das margens de lucro provocada tanto pelo aumento da concorrência, particularmente de empresas não-bancos, quanto pela crescente influência da tecnologia nos produtos e serviços bancários (Steiner e Teixeira, 1990), eleva a importância da Web para os bancos. Uma vez que a redução das margens de lucro se torna inevitável, a única solução para enfrentar este problema é a busca da redução de custos operacionais.

Essas vantagens de custos mais baixos de distribuição só deverão ser atingidas de fato, quando o home banking, mediante a Web, estiver sendo utilizado por grande número de usuários. Quando os volumes de operações pela Web atingirem níveis comparáveis ao de outros canais mais tradicionais de transação, é provável que a redução de custos vá ter grande impacto para os bancos.

Há quem aponte os problemas relacionados à administração de novo canal de distribuição dos produtos bancários, devido ao custo de integração dos diferentes canais e sistemas pré-existentes (Nehmzow, 1997). Por outro lado, pode-se considerar também que, talvez, a Web se apresente não como um canal a mais, mas como o canal que propiciará a integração dos demais sob uma interface comum (Gates III, 1999), reduzindo assim os custos de integração.

Em todos os casos analisados, a utilização de serviços de transação avançada não é muito significativa, mantendo-se em níveis inferiores a $10 \%$ nos três países considerados. Isto quer dizer que os serviços de oferta de dinheiro eletrônico e associação com lojas virtuais não têm ainda muito apelo junto aos bancos. A criação de bancos funcionando exclusivamente pela Web, ainda é fenômeno norte-americano, não tendo sido identificado no Brasil e na Espanha.

\section{Melhorar o Relacionamento}

Além de um canal de transação, a Web pode ser usada pelos bancos como canal de melhoria do relacionamento com os seus clientes. "Os serviços financeiros têm um componente de intangibilidade, o que faz com que a apreciação do serviço dependa muito da relação que se estabelece com o cliente", afirma o diretor de serviços virtuais de um grande banco espanhol (Gallego, 1998, p. 2). Além disso, o fato de a Web ser essencialmente uma tecnologia de front-end, faz com que ela afete diretamente o relacionamento do banco com seus clientes (White, 1997).

Pode-se dizer então que a grande vantagem que os bancos devem explorar sobre os seus concorrentes não-bancos será a confiança e o relacionamento já 
estabelecido com seus clientes (Cipparone, 1997). Há quem afirme que os bancos devem tornar-se integradores do sistema financeiro, orientados para o relacionamento com os clientes e não para a manutenção de contas correntes (Noam, 1996). E a Web pode ser o veículo para viabilizar este relacionamento dos bancos com seus clientes.

Estas são as seis características básicas da Web: interatividade, resposta imediata, conectividade, interoperabilidade, multimídia e facilidade de uso (Ware et al., 1998). Cada uma destas características pode contribuir para incrementar o relacionamento dos bancos com seus clientes. A seguir faremos uma descrição de cada uma destas características.

A natureza interativa da Web permite aos seus usuários um comprometimento muito mais ativo do que o possibilitado pela utilização de outras tecnologias. Enquanto pelos outros canais as informações são empurradas, independentemente do fato de serem ou não desejadas, com a Web o usuário busca a informação que quer, na dosagem que lhe é mais conveniente. Esta característica vai ao encontro da necessidade de uma parcela crescente da clientela de serviços financeiros, que é mais ativa no sentido de querer gerir o investimento de seus ativos financeiros, mais do que simplesmente deixá-los depositados e estáticos numa conta bancária (Gallego, 1998).

A Internet é excelente instrumento para coletar, integrar e distribuir informação, o que pode ser utilizado pelos bancos para oferecer uma resposta mais rápida às necessidades dos seus clientes. A velocidade da Internet é particularmente interessante no universo do mercado financeiro, no qual a capacidade de reação pronta pode significar a diferença entre ganhar ou perder na disputa por alguma oportunidade de investimento.

A extensa conectividade da Internet permite que pessoas e organizações consigam adquirir informação de forma muito mais fácil e barata do que já foi possível com outras tecnologias. Essa acessibilidade a informações, que nem mesmo estariam disponíveis pelos outros meios, gera nova realidade, na qual os bancos poderão adicionar valor aos seus serviços por meio de coordenação mais efetiva das fontes provedoras e distribuidoras de informação, entre as quais podem estar incluídos os seus próprios clientes.

A interoperabilidade da Web significa a independência de plataforma para o estabelecimento de uma conexão efetiva entre sistemas diferentes. Esta situação permite tanto o barateamento quanto a ampliação das comunicações entre bancos e seus clientes, superando as limitações do home banking, baseado em sistemas proprietários. 
Se hoje as informações financeiras ainda são baseadas fundamentalmente em textos e números, não é improvável que no futuro a utilização de gráficos, áudio e vídeo seja mais e mais comum (Kalakota, 1997). O uso de canal multimídia como a Web, por um lado, enriquece as possibilidades de representação de dados financeiros, atendendo a necessidades mais específicas de certos clientes; por outro lado, permite também atender àqueles que prefiram ver e falar com seres humanos antes de tomar uma decisão financeira, utilizando recursos de videoconferência.

Se a facilidade de uso da Web pode ainda ser questionada (Kessler, 1998), parece comprovado que um dos principais fatores do vertiginoso crescimento da Internet nos últimos anos é a maior simplicidade de utilização da Web, se comparada a outras tecnologias. Essa maior simplicidade de uso da Web se deve à sua interface gráfica padronizada e à crescente competência dos usuários no manejo de computadores. Não se pode esquecer também que os serviços bancários são utilizados por clientes com perfis muito diferentes entre si. Assim, os que devem beneficiar-se do uso do Internet banking são justamente aqueles de perfil social mais elevado e, conseqüentemente, mais acostumados ao uso de computadores.

Além desses fatores que a colocam como veículo que potencia as oportunidades de melhorias na oferta de serviços aos clientes, a Web pode também ajudar os bancos a desenvolver outras oportunidades, graças ao melhor relacionamento com os clientes. Umas destas oportunidades é a possibilidade de realização de venda cruzada (cross-selling), ou seja, a oferta de produtos diferentes a clientes que já são consumidores de outros produtos. O cross-selling pode ser indicador do nível de relacionamento entre os bancos e seus clientes (Rosa, 1999). Com a Web fica mais fácil coletar dados sobre os clientes com o objetivo de definir mais claramente o seu perfil. Identificar precisamente os clientes e seus hábitos de consumo ajuda o banco a vender novos produtos a velhos clientes.

Outra das oportunidades que o relacionamento mais intenso dos clientes com o banco pode permitir é o desenvolvimento de novos produtos customizados ou desenhados mais adequadamente às necessidades dos clientes. Tarefa que pode ser simplificada pela Web, a coleta sistemática de informações sobre as necessidades dos clientes levará ao banco um modelo de desenvolvimento de produto sintonizado com a demanda de seus atuais e futuros clientes.

É preciso ficar atento para o que já foi definido como o paradoxo do comércio eletrônico (Ernst \& Young, 1998). Por um lado a Web possibilita a maior interação da empresa e do cliente, graças à coleta mais constante de informações do cliente, o que, em princípio, tenderia a aumentar os vínculos do cliente com o banco. Por outro lado, a maior oferta de informações no mercado, proporciona- 
da pela mesma Web, faria com que o cliente ficasse mais motivado a buscar serviços mais vantajosos, onde quer que eles fossem oferecidos, reduzindo a necessidade de se vincular a um único fornecedor. Isso poderia incentivar o desenvolvimento de alianças estratégicas que colocassem instituições financeiras vendendo produtos umas das outras.

Usando o modelo descrito na seção anterior, observamos o nível de utilização dos serviços que melhoram o relacionamento dos bancos com seus clientes, acionistas e outros usuários dos seus sites. No nível de relacionamento básico, $e$ mail e formulários são as formas de o cliente fazer suas sugestões e reclamações ao banco. Está incluída aqui também a possibilidade de que o usuário se identifique para solicitar um relatório específico ou a descrição mais detalhada de serviços ou produtos.

A Tabela 4 mostra que o relacionamento, da mesma forma que acontece nos serviços da categoria divulgação, nos serviços de nível básico é padrão já completamente estabelecido nos sites dos bancos.

Tabela 4: Serviços de Relacionamento

\begin{tabular}{|l|c|c|}
\hline & $\begin{array}{c}\text { Relacionamento } \\
\text { básico }\end{array}$ & $\begin{array}{c}\text { Relacionamento } \\
\text { intermediário }\end{array}$ \\
\hline Brasil (maio/1999) & $96 \%$ & $41 \%$ \\
\hline Estados Unidos (janeiro/1999) & $98 \%$ & $66 \%$ \\
\hline Espanha (março/1999) & $89 \%$ & $45 \%$ \\
\hline
\end{tabular}

No nível de relacionamento intermediário estão ferramentas que correspondem a uma oferta de serviços que, além de adicionar algum valor às necessidades dos usuários, permite ao banco obter retorno mais preciso sobre o perfil dos usuários do site. Estão incluídas nesta categoria ferramentas que podem auxiliar o usuário na tomada de decisões financeiras mais simples, como a solicitação de um produto de empréstimo ou de investimento, e também a definição do perfil do investidor, que pode ajudar a direcioná-lo para produtos específicos do banco.

Os serviços neste nível nos Estados Unidos estão bem acima do encontrado na Espanha e no Brasil. É outro caso em que pode associar-se a oferta dos serviços diretamente com o nível de utilização da Web no país. Dada a simplicidade de implementação das ferramentas incluídas nesta categoria associada aos benefícios que elas podem trazer, pode estar aqui uma importante oportunidade de explorar serviços originais para a parcela mais afeita ao uso da Web, geralmente também a de maior rentabilidade para os bancos. 
O nível de relacionamento avançado está vinculado às possibilidades que a Web oferece de fornecer ao usuário um assessoramento personalizado e ainda trazer informações para o banco que contribuam diretamente no desenvolvimento de novos produtos. Classificam-se neste nível recursos como chat, fórum e videoconferência, que podem ser instrumentos para aconselhar usuários na tomada de decisões de investimento mais complexas ou ainda para organizar grupos de usuários na discussão de temas de interesse comum (Lebowitz, 1996).

Entre os quase 300 sites analisados, foi encontrado apenas um único que oferecia serviço que poderia ser classificado nesta categoria (Cia e Diniz, 1999). O Banco do Nordeste do Brasil (http://www.bnb.gov.br/) organiza, por meio do seu site, um fórum de debates sobre o Nordeste com um software de IRC (Internet Relay Chat) fornecido pelo próprio banco. As reuniões são trimestrais e organizadas em grupos de no máximo 20 participantes, podendo contar até com a presença on-line do presidente do banco. Uma lista de resoluções tiradas dessas reuniões é publicada no site, mostrando a eficiência da sua utilização. Apesar do potencial desses fóruns on-line (Lebowitz, 1996), na prática não têm sido muito utilizados pelos bancos.

\section{ConClusÓEs}

Como foi visto, a evolução das estratégias de adoção da Web pelos bancos foi norteada pela exploração de novo canal de divulgação de informações, pela busca de maior eficiência nas transações bancárias e de melhoria do relacionamento com clientes e outros usuários do site. A coleta de informações de sites foi baseada num modelo que permitiu - no tempo e em diferentes universos - a comparação dos serviços oferecidos na Web pelos bancos, trazendo contribuições para o melhor entendimento da evolução dos serviços bancários nos canais do comércio eletrônico.

É também preciso considerar que essa evolução tem sido impulsionada por uma variedade de objetivos no decorrer do tempo. Assim, quando não sentiam que a Web era um canal seguro para transações, os bancos foram para a Web para usar o seu potencial como canal de divulgação de informações e para garantir a posse do domínio da Internet.

Junto com a maior confiança na segurança oferecida pela Internet cresceu a estratégia de usar a Web como canal de transações, pois este poderia trazer economia no processamento de serviços bancários costumeiramente realizado em outros canais. Ao mesmo tempo que os bancos aderiam em grande número ao 
Web banking, se percebeu que quem não estivesse oferecendo este tipo de serviço poderia perder clientes, fazendo engrossar mais ainda a massa de bancos que ofereciam transações pela Internet.

Entretanto a economia real só virá com um crescimento muito expressivo da utilização da Web, quando ela rivalizar com os outros canais de distribuição de serviços bancários ainda hoje predominantes. A Web pode ser explorada também para ampliar o relacionamento com os clientes, com o objetivo de desenvolver serviços que sejam mais apropriados à sua necessidade e também de oferecer, a clientes de alta rentabilidade para o banco, mais produtos entre os já disponíveis na carteira, mediante a venda cruzada (cross-selling).

Há ainda outras motivações para a utilização da Web pelos bancos que, embora aparecendo com menos freqüência na literatura, também parecem significativas. Entre estas motivações vemos a possibilidade de conquistar novos clientes, a exploração de novas tecnologias e a criação de novas oportunidades de negócio.

Num mercado mais dinâmico e em constante mudança, existe a necessidade de estar sempre criando novas alternativas que satisfaçam as novas necessidades dos clientes. Por este aspecto, a Web pode ser excelente alternativa para os bancos que estão buscando o desenvolvimento de produtos inovadores. A infinidade de recursos interativos encontrados exclusivamente na Web pode ser fonte de criação de novos produtos para os bancos, que poderiam ser ofertados apenas no novo canal. Como vimos nas pesquisas feitas nos Web sites dos bancos, há muito campo para eles explorarem recursos mais interativos, criando serviços mais inovadores, incluídas aqui formas mais flexíveis de cobrar pelos serviços e produtos oferecidos.

Além disso, é importante para os bancos o aperfeiçoamento da capacidade de aprender com as novas tecnologias. Este aprendizado tecnológico, que pode ser propiciado pela Web, oferece aos bancos alternativas para se manterem sempre atualizados em termos do potencial de novas tecnologias, fator que tende a ser mais importante para enfrentar concorrentes num mercado no qual a habilidade de absorver e implantar serviços, baseados em tecnologia de informação, é fator crítico de sobrevivência.

A possibilidade de ampliação de mercado, com a expansão dos horizontes geográficos tradicionais de atuação, é uma das características mais atraentes da Web. Os bancos, empresas que trabalham com produtos e serviços que podem ser operados e transacionados por meio virtual, estão entre as empresas que mais podem beneficiar-se com esta ampliação dos horizontes geográficos da Web.

Estas outras motivações, ampliação de mercado, experimentar novas tecnologias e criar novos negócios, embora sejam potencialmente importantes, devem ser 
mais bem investigadas em pesquisas futuras, para se compreender a real preocupação dos bancos para com elas. Além de aparecerem com menos freqüência na literatura, os impactos dessas outras motivações são de mais longo prazo; só devem crescer em importância, quando o número de usuários da Web e o comércio eletrônico em geral forem muito mais significativos em termos absolutos.

Em meio a estas oportunidades descritas, há também desafios que os bancos devem enfrentar, para que tenham sucesso na utilização da Web, seja como canal de divulgação, seja para reduzir custos, seja mesmo para incrementar o relacionamento com os seus clientes.

Em primeiro lugar, é preciso considerar que quanto mais aumenta o comércio eletrônico e, conseqüentemente, a atuação dos bancos pela Web, mais se desenvolve a necessidade de aprimorar os meios de pagamento de utilização específica nas compras on-line. Os bancos, que ainda hoje têm participação majoritária no controle dos meios de pagamento, podem sofrer uma concorrência mais intensa de empresas que tenham mais agilidade para operar um novo tipo de moeda eletrônica. Tendo já assistido à erosão do seu mercado, graças à atuação agressiva de concorrentes de fora do universo bancário (Ernst \& Young, 1997), os bancos têm de ficar atentos para não perder mais esse espaço. Se a velocidade de adesão dos bancos à Internet for muito lenta, isto pode significar a perda do monopólio que ainda hoje mantém sobre os meios de pagamento (Cipparone, 1997).

Por participar de um mercado altamente regulamentado, os bancos são, por um lado, protegidos; mas, por outro, sofrem limitações com a regulamentação. O processo de desregulamentação ora em curso em muitos países, pode trazer benefícios e ameaças aos bancos. Um mercado menos regulamentado pode oferecer mais opções de atuação à concorrência que os bancos sofrem das organizações não-bancárias. Ao mesmo tempo, as barreiras de atuação geográfica dos bancos podem ser reduzidas, ampliando-se a possibilidade de atuação em novos mercados, no que a utilização da Web seria absolutamente estratégica. Além disso, a regulamentação do comércio eletrônico ainda não está consolidada, particularmente no que diz respeito ao uso de dinheiro eletrônico (King, 1996), que terá impacto direto sobre os bancos.

Outro problema potencial é a administração de novo canal em conjunto com os já existentes e a integração destes diversos canais a bases de dados comuns. Este é problema que os bancos já enfrentam há tempo, com a crescente demanda dos clientes de uma oferta diversificada de opções para utilizar os serviços bancários. A administração eficiente dos diversos canais e também a já mencionada possível integração numa interface comum, deve ser crítica para os bancos.

Por último, outro problema que avassala os bancos é a necessidade de se 
adaptarem organizacionalmente a uma nova realidade que vai demandar respostas mais rápidas e eficazes às alterações no mercado. $\mathrm{O}$ banco on-line de sucesso terá estrutura organizacional muito diferente daquela dos bancos tradicionais, em que o volume principal das transações ocorre no ambiente da agência e em outro canais menos interativos que a Internet. Para se adaptarem à nova realidade na qual a predominância do uso da Web será cada vez maior, os bancos terão de administrar mudanças organizacionais importantes com muita competência e criatividade.

\section{Nota}

${ }^{1}$ Não foram poucos os bancos que enfrentaram situação semelhante à vivida hoje pela America On-Line na disputa com uma empresa brasileira que registrou, há alguns anos, o domínio aol.com.br.

\section{REFERÊNCIAS BiBLIOGRÁFICAS}

ALBERTIN, A. L.

Comércio eletrônico : um estudo no setor bancário. In: XXII ENCONTRO ANUAL DA ANPAD (1998 : Foz do Iguaçu). Anais Eletrônicos... Foz do Iguaçu : ANPAD, 1988.

BANCOS latinos são mais ousados na Internet.

Gazeta Mercantil, São Paulo, 23 jul. 1997.

CIA, J. N. S.;

DINIZ, E.

O uso da Internet para a divulga- ção das informações financeiras dos bancos. In: XXIII ENCONTRO ANUAL DA ANPAD (1999 : Foz do Iguaçu). Anais Eletrônicos... Foz do Iguaçu : ANPAD, 1989.

\section{CIPPARONE, M.}

Internet banking services vs. proprietary solutions : why the Internet is deemed to succeed. [online] Disponível na Internet via WWW.URL : http:// www.arraydev.com/commerce/ JIBC/9602-1.htm. Journal of Internet Banking and Commerce, v. 1, n. 2, Feb. 1996. 
The consequences of electronic delivery channels on the retail banking industry.[online] Disponível na Internet via W W W. U R L : h t t p : // www.arraydev.com/commerce/ JIBC/9702-15.htm. Journal of Internet Banking and Commerce, v. 2, n. 2, Mar. 1997.

\section{CUEVAS, J.}

The Internet bank horizon : bleak or bright for community banks? Disponível na Internet via W W W. U R L : h t t p : / / www.arraydev.com/commerce/ JIBC/9811-14.htm. Journal of Internet Banking and Commerce, v. 3, n. 3, Nov. 1998.

DIAZ, A. N.;

GERTNER, D.

Marketing na Internet e comportamento do consumidor : investigando a dicotomia hedonismo vs. utilitarismo na WWW. In: XXII ENCONTRO ANUAL DA ANPAD (1998: Foz do Iguaçu). Anais Eletrônicos... Foz do Iguaçu : ANPAD, 1988.

\section{DINIZ, E. H.}

Serviços oferecidos por bancos em Web sites nos EUA - Janeiro/ 1999. Centro de Excelência Bancária - EAESP/FGV, São Paulo, fev. 1999a. Relatório de pesquisa.
Serviços oferecidos por bancos em Web sites na Espanha - Março/1999. Centro de Excelência Bancária - EAESP/FGV, maio 1999b. Relatório de pesquisa.

Serviços oferecidos por bancos em Web sites no Brasil - Maio/ 1999. Centro de Excelência Bancária - EAESP/FGV, jul. 1999c. Relatório de pesquisa.

Web banking no Brazil e nos EUA. In: 16TH ANNUAL CONFERENCE OF THE BALAS (1999 : New Orleans). Proceedings... New Orleans : BALAS, 1999c.

E-COMMERCE \& connecting the customer.

Technology in banking and financial services. Ernst \& Young LLP, 1998. Special report.

FS Internet value creation study.

Ernst \& Young LLP, Jan. 1999. Mainspring.

\section{GALLEGO, N.}

La banca en Internet : ahora empieza el despliegue.[online] Disponível na Internet via WWW.URL : http://www.idg.es/ iworld/199810/articulos/ banca.asp. IWorld, año II, n. 9, Oct. 1998. 
GATES III, W. H.

Business@ the speed of thought : using a digital nervous system. ISBN : 0-446-52568-5. New York, 1999.

GONÇALVEZ FILHO, C. et al.

Comércio eletrônico na Internet: uma pesquisa exploratória no mercado consumidor. In: XXII ENCONTRO ANUAL DA ANPAD (1998 : Foz do Iguaçu). Anais Eletrônicos... Foz do Iguaçu : ANPAD, 1988.

KALAKOTA, R.

The impact of cybercommunications on traditional financial services. [online] Disponível na Internet via WWW.URL : http:// ww w.citi.columbia.edu/ cybcompap/ravi.htm. CITI Working Paper Series, Aug. 1997.

KALAKOTA, R.;

WHINSTON, B. A.

Electronic commerce : a manager's guide. ISBN 0-20188067-9. [S.1.], 1997.

KESSLER, G. C.

Credit unions and the Internet in the $21^{\text {st }}$ century. [online] Disponível na Internet via W W W. U R L : h t t p : / / Www.vtac.org/tutorials/ csccu.html. CONSTITUTION STATE CORPORATE CREDIT UNION ANNUAL MEETING
(1998 : [S.1.]). Proceedings... [S.1. : s.n.], 1998.

KING, J.

Cyberbanking. [online] Disponível na Internet via WWW.URL : http://law.ttu.edu/ cyberspc/jour4.htm. Nov. 1996.

\section{LEBOWITZ, J.}

The dawning of a new era. Mortgage Banking, June 1996.

MANAGING the value network.

Technology in banking and financial services. Ernst \& Young LLP, 1997. Special report.

NEHMZOW, C.

The Internet will shake banking's medieval foundations. [online] Disponível na Internet via W W W. U R L : h t t p : / / Www.arraydev.com/commerce/ JIBC/9702-01.htm. Journal of

Internet Banking and Commerce, v. 2, n. 2, Mar. 1997.

NOAM, E. M.

Electronics and the dim future of banks. [online] Disponível na Internet via WWW.URL : http:// www.columbia.edu/dlc/wp/citi/ c i t i n o a m 13 . h t m 1 . CONFERENCE ON ELECTRONIC BANKING OF THE FUJITSO RESEARCH INSTITUTE (1996: [S.1.]). Proceedings... [S.1. : s.n.], 1996. 
PECENIK, M.

Italian banks charging into the Internet. [online] Disponível na Internet via WWW.URL : http:// www.arraydev.com/commerce/ JIBC/9604-8.htm. Journal of Internet Banking and Commerce, v. 1, n. 4, June 1996.

ROSA, F. DE.

Cross-selling and data mining in retail banking : basic data structure. In: 16TH ANNUAL CONFERENCE OF THE BALAS (1999 : New Orleans). Proceedings... New Orleans : BALAS, 1999.

SATHYE, M.

Internet banking in Australia. [online] Disponível na Internet via WWW.URL : http:// www.arraydev.com/commerce/ JIBC/9704-27.htm. Journal of Internet Banking and Commerce, v. 2, n. 4, Sept. 1997.

SEITZ, J.;

STICKEL, E.

Internet banking - an overview. [online] Disponível na Internet via WWW.URL : http:// www.arraydev.com/commerce/ jibc/9801-8.htm. Journal of Internet Banking and Commerce, v. 3, n. 1, Jan. 1998.
SEYBOLD, P. B.;

MARSHAK, R. T.

Customers.com : how to create a profitable business strategy for the Internet and beyond. ISBN 08129-3037. New York, 1998.

STEINER, T. D.;

TEIXEIRA, D. B.

Technology in banking : creating value and destroying profits. ISBN 1-55623-150-4. [S.1.], 1990.

VIEIRA, B. L. A;

VIANA, D. A;

ECHEVESTE, S. S.

Comércio eletrônico via Internet: uma abordagem exploratória. In: XXII ENCONTRO ANUAL DA ANPAD (1998 : Foz do Iguaçu). Anais Eletrônicos... Foz do Iguaçu : ANPAD, 1988.

WARE, J. et al.

The search for digital excellence. ISBN 0-07-027057. [S.1.], 1998.

WHITE, L. J.

Electronic banking? Whoa, not so fast! : reports on the death of the paper check have been greatly exaggerated. Disponível na Internet via WWW.URL : http:/ /www.stern.nyu.edu/Webzine/ $\mathrm{S}$ t e $\mathrm{r} n \mathrm{~b}$ u $\mathrm{s}$ i e s s/ S pring_S u m m e r $97 /$ electronic.html. Aug. 1997. 